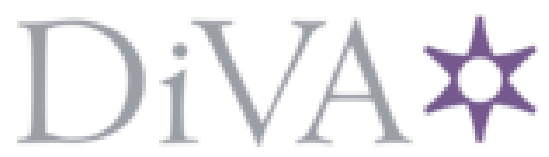

http://www.diva-portal.org

\title{
Postprint
}

This is the accepted version of a paper published in Journal of Asthma. This paper has been peerreviewed but does not include the final publisher proof-corrections or journal pagination.

Citation for the original published paper (version of record):

Lind, N., Nordin, M., Palmquist, E., Claeson, A., Millqvist, E. et al. (2015)

Coping and Social Support in Asthma and Allergy: The Västerbotten Environmental Health Study.

Journal of Asthma, 52(6): 622-629

http://dx.doi.org/10.3109/02770903.2014.991970

Access to the published version may require subscription.

N.B. When citing this work, cite the original published paper.

Permanent link to this version:

http://urn.kb.se/resolve?urn=urn:nbn:se:umu:diva-97461 
Running head: Coping and Social Support in Asthma and Allergy

\section{Coping and Social Support in Asthma and Allergy: The Västerbotten Environmental Health Study}

Nina Lind ${ }^{1}$, Maria Nordin ${ }^{1}$, Eva Palmquist ${ }^{1}$, Anna-Sara Claeson ${ }^{1}$, Eva Millqvist $^{2}$ and Steven Nordin ${ }^{1}$

${ }^{1}$ Department of Psychology, Umeå University, Umeå, Sweden

${ }^{2}$ Department of Allergology, Institution of Internal Medicine, the Sahlgrenska Academy at University of Gothenburg, Gothenburg, Sweden

*Corresponding author: Nina Lind, Department of Psychology, Umeå University, SE-901 87 Umeå, Sweden; e-mail: nina.lind@ psy.umu.se; +46 (0)90 - 7867843.

Keywords: allergic rhinitis, atopic dermatitis, atopy, quality of life, epidemiology 


\begin{abstract}
Objectives: Asthma and allergy are stressful conditions that require coping strategies and social support to reduce stress and enhance health-promoting behavior. However, research is limited regarding coping and social support in asthma and allergy. The aim was to better understand use of different coping strategies and perceived social support in low and high severity (exacerbation frequency) of asthma and allergy. Methods: Population-based data were used to provide ratings of coping strategies (Study I) and social support (Study II) from 124 and 94 participants, respectively, with asthma and/or allergy, categorized as low or high in severity. Problem- and emotion-focused coping strategies were assessed as well as emotional, instrumental and informative social support from seven sources. Results: Study I showed that avoiding certain environments (problem-based coping) and trying to accept one's situation (emotion-based) were the most commonly used coping strategies. These behaviors did not differ due to severity. Study II showed that more emotional than instrumental and informative support was perceived. The highest rated support sources were the partner, family members, and the healthcare system. More social support was reported in low compared to high asthma/allergy severity. Conclusion: The most commonly used coping strategies in the population of persons with these four types of asthma and allergy are avoiding certain environments and trying to accept one's situation. More emotional support than instrumental and informative is perceived to be received, and most of the support is received from one's partner and other family members, and least from authorities and patient associations/support groups.
\end{abstract}




\section{Introduction}

Despite contradicting results [1], an increasing number of persons worldwide suffer from asthma and allergy [2-3]. Prevalence rates for Sweden are 8.3\% for asthma [1], 13-17\% for allergic rhinitis [4], and 11-15\% for atopic dermatitis [5]. The symptomology is characterized by shortness of breath and wheezing in allergic and non-allergic asthma, by nasal congestion and discharge in allergic rhinitis, and by skin lesion and eczema in atopic dermatitis. With the exception of non-allergic asthma (caused by e.g. exercise and cold air), these conditions are referred to as atopy.

Asthma/allergy has been found to be associated with distress, such as stress, anxiety, depression, worries and mental and physical exhaustion (burnout) [6-12], which might act directly on somatic disease via enhanced activation of the immune system [13]. Importantly, the illness itself may be a stressful factor that can increase the need and usage of coping strategies [14] and social support [15]. At present, most patients take medication for controlling their asthma/allergy symptoms since immunotherapy may not be easily accessible. However, coping strategies and social support may not only alleviate the stress and other aspects of distress associated with asthma/allergy, but may also alleviate the asthma/allergy. Wright [16] has in a review provided strong support for the impact of stress on neuroimmunoregulation and oxidative stress pathways, which, in turn, may affect biological hypersensitivity to environmental stimuli characteristic of atopic disorders. The main objective of the present study was therefore to investigate use of coping strategies and social support in asthma and allergy.

Coping is defined as thoughts, behaviors and actions to solve problems, handle emotions, and thereby reduce stress, and the individual's personal experience with effective coping strategies is the basis for the selected strategy used in a particular situation, and reflects personal 
coping style [17]. The positive or negative effect of different coping strategies depends on the situation. The most referred types of coping strategies are problem- and emotion-focused [17]. Emotion-focused coping includes acknowledging, understanding and expressing the emotion, and is more likely to occur in taxing, unpredictable and uncontrollable situations that persons appraise as unchangeable, which is important in order to avoid and prevent depression. Problem-focused coping, on the other hand, includes analyzing, reducing or eliminating stressors, is more likely to be used in situations that are perceived as threatening or dangerous, but believed to be susceptible to change [17-18].

Social support is an important part of coping, and can help either in solving a problem that a stressor poses, or to comfort and help dealing with the emotions that the stressor elicits. It can be defined as the perception of being cared for, accepted and esteemed by others [19], and is often divided into emotional, instrumental and informative support [20-21]. Extensive literature shows beneficial effects of adequate social support in chronic disease [22] and in promoting health behavior [15]. Social support may affect coping according to the main-effect hypothesis, suggesting that the individual with strong perception of social support has a feeling of being loved and cared for, which has a permanent positive effect on the individual's general health [2324]. In that sense the support may serve as a resource of coping by influencing the choice of coping strategy in a stressful situation [25]. In order for social support to be stress-reducing it has been proposed that it must match the stressor $[16,26]$. Thus, specific needs should be met by specific types of social support, meaning that also the sources of support must be specific to the stressor. In disease, in particular, specific needs can be met by specific sources. For instance, information about the disease and its treatment is presumably best provided by healthcare professionals, information about societal resources and rights by associations and support groups, and emotional support by family and friends. 
There is clearly a lack of studies on social support in both allergic rhinitis and atopic dermatitis [27]. Due to these conditions being associated with stress [12-13], and since social support buffers against stress [15], there is reason to believe that atopic mechanisms underlying asthma that are related to social support through mediation of stress also may be valid for allergic rhinitis and atopic dermatitis.

The close relation between coping and social support calls for a broad approach by investigating both aspects for better understanding their role in asthma and allergy. The apparent importance of type and source of social support, motivates a broad approach in such investigations as well as different types of coping strategies. Furthermore, the role of asthma severity in quality of life [28] evokes the question as to whether severity of asthma/allergy plays a role in coping and social support.

The general aim of this work, by means of two studies, was to gain better understanding for use of different coping strategies and various types and sources of social support in low and high severity of asthma/allergy (frequency of symptom exacerbation). In Study I we investigated use of problem- and emotion-focused coping strategies in low and high severity, and in Study II we studied perceived social support of different types from different sources in low and high severity. The types of social support included instrumental, emotional and informational coping, and the sources of support included the partner, other family members, friends, co-workers, the healthcare system, authorities, and patient associations/support groups. This was addressed by use of data from a population-based questionnaire study. Whereas specific types of asthma and allergy may be addressed in future studies, a first step was taken here to study coping strategies and social support in asthma and allergy in general that included allergic and non-allergic asthma, allergic rhinitis and atopic dermatitis. 


\section{Methods}

\section{Study population and study groups}

The two studies were conducted within the Västerbotten Environmental Health Study, which is an embracing name for different investigations on the same general population regarding various forms of environmental hypersensitivity. The study population, inhabitants in the county of Västerbotten in Northern Sweden, has an age and sex distribution that is similar to that of Sweden in general [29]. A random sample, drawn from the municipal register, of 8600 individuals aged 18 to 79 years was invited to participate. The sample was stratified for age and gender according to the age strata $18-29,30-39,40-49,50-59,60-69$, and 70-79 years. Of the 8600 individuals, 8520 could be reached, among whom 3406 (40.0\%) volunteered to participate. Age and sex distributions for the sample have been described previously [30].

The individuals selected for the two studies had one or several of the diagnoses i) allergic asthma, ii) non-allergic asthma, iii) allergic rhinitis, and iv) atopic dermatitis that they reported had been given by a physician, which constituted the asthma/allergy group. If they had other diagnoses of environmental sensitivities (e.g. multiple chemical sensitivity), inclusion required that they reported the asthma/allergy to be more disturbing than the other environmental sensitivity. Additional inclusion criteria were responding to questions in the questionnaire about frequency of asthma/allergy exacerbations (Study I and II), coping strategies (Study I) and social support (Study II).

One hundred and eighty-seven participants met the inclusion criteria for Study I, of which 124 had low frequency of asthma/allergy symptom exacerbation, and 63 had high frequency. The two subgroups are described in Table 1 with respect to demographics and diagnoses given by a physician, including number of comorbid and multimorbid forms of asthma/allergy. The entire 
population-based sample $(n=3406)$ is described as well for comparison. One-way analyses of variance (ANOVAs) and chi-square analyses showed no significant differences between the two symptom frequency groups in Study I on any of the descriptive variables in Table $1(\mathrm{p}>0.12)$, with the exception of the diagnosis multiple chemical sensitivity being more prevalent in the high frequency group $(\mathrm{p}<0.05)$.

[Table 1 about here]

Ninety-four participants met the inclusion criteria for Study II, of which 57 had low frequency of asthma/allergy symptom exacerbation, and 37 had high frequency. As for Study I, the two subgroups are described in Table 1 with respect to demographics and diagnoses given by a physician. One-way ANOVAs and chi-square analyses showed no significant difference between the two symptom frequency groups in Study II on any of the variables in Table 1 $(\mathrm{p}>0.27)$.

\section{Questionnaire instruments}

The questionnaire included questions pertaining to demographics, physician-based diagnoses, and questions about coping strategies and social support. Frequency of asthma/allergy symptom exacerbation was assessed with the question "How often do you in general have asthma/allergy exacerbations?" (daily/once or a few times per week/once or a few times per month). Once or a few times per month (monthly) was considered as low in exacerbation frequency, and daily and once or a few times per week (weekly) were considered as high in frequency.

Coping strategies were assessed with four statements about problem-focused strategies, and four statements about emotion-focused strategies which are shown in Table 2. Each statement was rated on a 7-point scale ranging from 'Not at all (0)' to 'A very large extent (6)', and used separately in the analysis. The absolute zero point, representing no use at all, and the use of 
equidistant scale numbers with descriptors only at the end points, implies that the procedure would provide ratio-scale data. An almost identical version of this instrument has previously been used to study coping in chemical intolerance [31]. The statements were based on theories by Lazarus and Folkman [17], and effort was made to fit the statements to the study population's everyday hassles and needs.

[Table 2 about here]

Social support was assessed with the three questions "To what extent do you perceive that you receive (1) understanding for..., (2) help with information about..., and (3) practical help with... ...your asthma/allergy?” Thus, the questions referred to emotional support (operationalized as understanding), instrumental support (practical help), and informative support (help with information). For each question the participant was instructed to respond with respect to each of seven social support sources: one's partner, other family members, friends, coworkers, the healthcare system, authorities, and patient associations/support groups. Each of these 21 items was rated on a 7-point scale ranging from "Not at all (0)" to "To a very large extent (6)", identical with the scale for coping strategies. As for the assessment of coping, an almost identical version of this instrument has previously been used to study social support in chemical intolerance [31].

\section{Procedure}

The participants were mailed the questionnaire, to be returned by mail with prepaid postage. Non-responders received up to two reminders. All participants responded to the questionnaire during the period March-April, 2010, before the onset of the pollen season in Västerbotten. The study was conducted in accordance with the Helsinki Declaration and approved by the Umeå Regional Ethics Board (Dnr 09-171M). All participants gave their informed consent to 
participate.

\section{Statistical analysis}

The Statistical Package for the Social Sciences (SPSS, IBM Corp., IBM SPSS Statistics for Windows, Version 22.0, Armonk, NY, USA) was used to analyze the data. One-way ANOVAs and chi-square analyses (Fisher's exact test for cell count $<5$ ) were computed to compare the two severity groups, separately for Study I and II, with respect to demographics and diagnoses given by a physician (Table 1). To test whether type of strategy and disease severity were associated with degree of usage of coping, two-way mixed model ANOVAs were conducted in Study I. Separate ANOVAs were conducted for problem-focused and emotion-focused strategies, with type of strategy (four levels for both problem- and emotion-focused strategies) as a within group factor, and symptom frequency (two levels: low and high) as a between group factor. To test whether type of support, source of support and disease severity were associated with degree of perceived social support, a three-way mixed model ANOVA was conducted in Study II. Support type (three levels: understanding, practical help, and help with information) and support source (seven levels: one's partner, other family members, friends, co-workers, the healthcare system, authorities, and patient associations/support groups) were used as within-group factors, and symptom frequency (two levels: low and high) as a between-group factor. Greenhouse-Geisser correction was applied in all ANOVAs. The $\alpha$-level was set at 0.05 , except for post-hoc analyses with one- or two-way ANOVAs comparing pairs of support sources, for which an $\alpha$-level of 0.01 was chosen due to a large number of pairwise comparisons.

\section{Results}




\section{Study I: Coping strategies}

Mean ratings of usage of problem-focused or emotion-focused coping strategies are presented in Figure 1. Results from the two-way ANOVAs are presented in Table 3. There was a significant association between strategy type and degree of usage of coping for both problem- and emotionfocused coping, but no significant association between symptom frequency and usage of coping, and no significant strategy type $\times$ symptom frequency interaction. Regarding problem-focused coping, post-hoc, one-way ANOVAs showed that "avoiding environments" (used most; Figure 1) was used to a significantly larger degree than "seeking information" (used least; $\mathrm{p}<0.01$ ). No other significant pair-wise differences were found. For emotion-focused coping, post-hoc, oneway ANOVAs showed that "trying to accept the situation" was used to a significantly larger degree than "re-prioritizing" and "eating, drinking and smoking", that "re-prioritizing" was used to a larger degree than "eating, drinking and smoking", and that "trying not to think about it" was used to a larger degree than "eating, drinking and smoking" ( $\mathrm{p}<0.01$; Figure 1). No other significant pair-wise differences were found. In absolute terms, the two most used problemfocused strategies were "avoiding environments" and "seeking healthcare", and the two most used emotion-focused strategies were "trying to accept the situation" and "trying not to think about it". The ratings for these strategies had a mean corresponding to the upper half of the scale used (from 'Not at all (0)' to 'To a very large extent (6)').

[Figure 1 and Table 3 about here]

\section{Study II: Social support}

Mean ratings of perceived social support for the two symptom frequency groups are presented in Figure 2. Results from the three-way ANOVA, presented in Table 4, yielded significant associations between support type and degree of social support, between support source and 
degree of social support, and between symptom frequency and degree of social support, and significant support type $\times$ support source and support type $\times$ support source $\times$ symptom frequency interactions.

These results suggest that more understanding (emotional) than practical help (instrumental) and help with information (informational) was perceived to be received (Figure 2). For support source, most support was perceived to be received from one's partner, other family members, and the healthcare system, followed by friends, and then by co-workers. Least support was perceived to be received from authorities and patient associations/support groups, independent of symptom frequency. The association between symptom frequency and degree of social support can be referred to higher social support in low symptom frequency than in high frequency (Figure 2).

In absolute terms, degree of emotional support varied from moderate to fairly high symptom exacerbation frequency, whereas instrumental and informational support varied from fairly low to moderate (cf. Figure 2). These variations within support type can partly be referred to support source and partly to symptom frequency of asthma/allergy exacerbation. Thus, in general, moderate to fairly high support was perceived to be received from the partner, other family members, and the healthcare system; moderate support from friends and co-workers; fairly low to moderate support from authorities; and low support from patient associations/support groups. For symptom frequency, moderate to fairly high social support was perceived among those with low symptom frequency, and fairly low to moderate support among those with high frequency (Figure 2).

The significant interaction between support type and support source motivated further posthoc, two-way ANOVAs. These yielded significant interactions when including the support types understanding and practical help, understanding and help with information and practical help and 
help with information. This suggests that the order of degree of social support from the different support sources differs between all three support types (cf. Figure 2).

The three-way ANOVA, (support type $\times$ support source $\times$ symptom frequency), yielding a significant interaction, may predominantly be referred to lower rather than higher support in higher symptom frequency compared to low severity regarding practical help from the partner.

[Figure 2 and Table 4 about here]

Post-hoc, two-way (support type $\times$ support source) ANOVAs showed significantly higher ratings for understanding than for practical help, and for understanding than for help with information, but no significant difference between practical help and help with information. The post-hoc, two-way (support type $\times$ support source) ANOVAs further showed significant differences between all pairs of support sources $(\mathrm{p}<0.01)$, except for between one's partner and other family members, one's partner and the healthcare system, other family members and the healthcare system, friends and the healthcare system, and authorities and associations/support groups (cf. Figure 2).

\section{Discussion}

A broad approach was taken in the present work to gain understanding for important aspects of coping usage and perceived social support in low and high severity of asthma and allergy. These aspects included type of coping strategy as well as type and source of social support.

The results showed that the most used coping strategies in the sample were avoiding certain environments and seeking health care (problem focused), to accept the situation, and to not think about the asthma/allergy (emotion focused). Regarding avoiding the environment that might affect one's health, previous studies have found that avoidance-oriented strategies can in fact 
affect health in a negative way, as it may result in more effective coping strategies not being used [32]. One effective strategy is accepting the situation, which can be a better way of handling the disease compared to avoiding environments, which instead can lead to isolation [33] as it may results in decreased opportunities for social support, and probably also the amount of perceived social support. Thus, accepting the situation taps on the concepts of acknowledging and understanding it, and consequently the emotions that arise from it.

Yellowless and associates [34] have studied denial in asthma (using the term avoidance), and found it to be a commonly adapted strategy among asthmatics, and described by the authors to protect against fear, anxiety and depression. This coping strategy can in the current study be referred to as "trying not to think about the asthma/allergy", which, in accordance with the study by Yellowless and associates, was found to be commonly used. Denial is a form of emotional regulation such that the way the individual thinks about the stressor is modified, rather than modifying the stressor itself. It has been found to be a significant risk factor for asthma attacks, attendance at hospital emergency departments, and near-fatal asthma attacks [35].

Acceptance may be an important factor when handling the emotions surrounding everyday life in chronic illness, such as asthma/allergy. Trying to accept the situation was found to be the most commonly used emotion-focused strategy. This is a positive outcome since acceptance in prior studies has been found to result in decreased distress [36], to be the best adaptive coping strategy among asthmatics [37], and to be critical in decreasing disease severity [38]. Taken together, these results support prior findings of accepting the situation being a common strategy [33].

In contrast to results of Sexton et al. [39], no significant difference between high and low severity was presently found. The discrepancy between studies may be due to the participants in 
that study being categorized as mild, moderate and severe in asthma based on medical records of pulmonary function, whereas the categorization in the present studies was based on self-reports.

Regarding social support, the results suggest, in general, that persons with asthma/allergy perceive more emotional (understanding) than instrumental (practical help) and informational (help with information) support. However, the order of degree of social support from the different support sources was found to differ to some extent depending on support type, which is in line with previous research [40-41]. Thus, most support appears to be given from a partner and family members, and least support from support groups and authorities.

It has been proposed that for social support to be health beneficial it should match the stressor [26]. Thus, specific needs, especially in cases of disease, should be met by specific types of social support, meaning that also the source of support should be specific to the stressor. In this sample the main type of support that the participants were given was emotional support of understanding. Even if support is provided from the required source it may still not be sufficient for the afflicted person. A previous study of asthmatics reported the main support sources to be the partner and family members, but that the support was not perceived to be enough, and that those closest to the asthmatic persons did not know what it was like to live with the illness [42].

The present results suggest that those with less severe asthma/allergy receive more social support than those with a more severe condition. It is possible that persons surrounding those with asthma/allergy may not have the stamina to maintain a good support system, and that the persons with severe asthma/allergy may choose to limit their contact with those who they perceive as non-supporting [43]. It is reasonable to assume that the extent of social support provided by the surrounding will decline over time, as the afflicted individual develops more efficient coping strategies to deal with the condition. Moreover, for social support, authorities were not clearly defined in this study, although the concept was intended to be referring to the 
social insurance agency, or other similar instances, which is part of the Swedish Government Agency that is responsible for large parts of the public welfare system.

There are strengths and limitations of the two studies to be mentioned. The inhabitants in the county of Västerbotten in Northern Sweden have an age and sex distribution that is similar to that of Sweden in general [29]. This enhances the possibility of generalization to persons with asthma/allergy in the general Swedish population and other similar populations. However, among the randomly selected individuals, only $40 \%$ volunteered. This is a somewhat low percentage, with consequences for the representativeness. Information on age and gender was available for those who declined participation in this study, and the largest proportion of non-responders was found among young men. However, how this may have affected the results is difficult to say. Other limitations of this study regard the questions used for assessing coping strategies and social support since these have not been validated. They can be considered to have good face validity [44], although this aspect of validity may not be considered as particularly important.

Yet another limitation is that a rather large proportion of the participants did not respond to questions about social support. A possible reason may be that some of the sources of support were not applicable due to not having a partner or coworkers, or due to purposely limiting the contact with those who they perceive as non-supporting [43].

In the questionnaire instrument for social support there was no alternative for the participants to state that the support source was not applicable. This is a limitation since not responding to a certain source may be due to purposely having excluded contact with those who were perceived as non-supporting. This may have resulted in an overestimation of the degree of perceived support. Another limitation regarding coping strategies is that other strategies than those eight assessed in this study may be used in asthma/allergy. The questionnaire used was chosen since it was successfully used in another type of environmental intolerance [31], and since 
no validated instrument is available for asthma/allergy. Thus, future studies should aim at developing an asthma/allergy-specific questionnaire instrument for coping and social support. In addition, future large-scale studies are needed for investigating coping and social support in different types of asthma/allergy.

In conclusion, despite the limitations, the results from the samples in the present two studies suggest that avoiding certain environments, seeking health care, trying to accept the situation, and not thinking about the condition are commonly used problem- and emotion-focused coping strategies in the population of persons with the studied forms of asthma/allergy.

Regarding perceived social support, the findings suggest that, in general, emotional support among persons with asthma/allergy is provided more than instrumental and informative support, and that most support is given from one's partner and other family members, and least from authorities and patient associations/support groups. 


\section{References}

1. Lötvall J, Ekerljung L, Rönmark EP, Wennergren G, Lindén A, Rönmark E, Torén K, Lundbäck B. West Sweden Asthma Study: prevalence trends over the last 18 years argues no recent increase in asthma. Respir Res 2009;10.

2. von Mutius E, Weiland SK, Fritzsch C, Duhme H, Keil U. Increasing prevalence of hay fever and atopy among children in Leipzig East Germany. The Lancet 1998;351:862-866.

3. Subbarao P, Mandhane PJ, Sears MR. Asthma: epidemiology etiology and risk factors. Can Med Assoc J 2009;181:181-190.

4. Nihlén U, Greiff L, Montnemery P, Löfdahl CG, Johannisson A, Persson C, Andersson M. Incidence and remission of self-reported allergic rhinitis symptoms in adults. Allergy 2006;61:1299-1304.

5. Rönmark EP, Ekerljung L, Lötvall J, Wennergren G, Rönmark E, Toren K, Lundbäck B. Eczema among adults: prevalence risk factors and relation to airway diseases Results from a large-scale population survey in Sweden. Brit J Dermatol 2012;166:1301-1308.

6. Liu LY, Coe CL, Swenson CA, Kelly EA, Kita H, Busse WW. School examinations enhance airway inflammation to antigen challenge. Am J Respir Crit Care Med 2002;165:1062-1067.

7. Wainwright NW, Surtees PG, Wareham NJ, Harrison BD. Psychosocial factors and asthma in a community sample of older adults. J Psychosom Res 2007;62:357-361.

8. Black PH. Stress and the inflammatory response: A review of neurogenic inflammation. Brain Behav Immun 2002;16:622-653.

9. Lind N, Nordin M, Palmquist E, Nordin S. Psychological distress in asthma and allergy: the Västerbotten Environmental Health Study. Psychol Health Med 2014;19:316-323. 
10. Rand CS, Wright RJ, Cabana MD, Foggs MB, Halterman JS, Olson L, Taggart V. Mediators of asthma outcomes. J Allergy Clin Immunol 2012;129:136-141.

11. Yonas MA, Lange NE, Celedon JC. Psychosocial stress and asthma morbidity. Curr Opin Allergy Clin Immunol 2012;12:202.

12. Mösges R, Klimek L. Today’s allergic rhinitis patients are different: new factors that may play a role. Allergy 2007;62:969-975.

13. Mitschenko AV, Lwow AN, Kupfer J, Niemeier V, Gieler U. Atopic dermatitis and stress? How do emotions come into skin? Hautarzt 2008;59:314-318.

14. Tijhuis MAR, Flap HD, Foets M, Groenewegen PP. Social support and stressful events in two dimensions: life events and illness as an event. Soc Sci Med 1995;40:1513-1526.

15. Cohen S, Wills TA. Stress social support and the buffering hypothesis. Psychol Bull 1985;98:310-357.

16. Wright RJ. Stress and atopic disorders. J Allergy Clin Immunol, 2005;116:1301-1306.

17. Lazarus RS, Folkman S. Stress Appraisal and coping. c1984. 456 p.

18. Snyder CR. Coping: The psychology of what works. Oxford University Press; c1999.

19. Pierce GR, Lakey B, Sarason IG, Sarason BR. Sourcebook of social support and personality Springer; c1997.

20. House JS, Landis KR, Umberson D. Social relationships and health. Science 1988;241:540545.

21. Lakey B, Cohen S. Social support theory and measurement. Social support measurement and intervention: A guide for health and social scientists; c2000. 29 p.

22. Cohen S, Underwood LG, Gottlieb BH. Eds; Social Support Measurement and Intervention: A Guide for Health and Social Scientists. New York: Oxford University Press; c2000. 
23. Compas BE, Slavin LA, Wagner BM, Vannatta K. Relationship of life events and social support with psychological dysfunction among adolescents. J Youth Adolesc 1986;15:205221.

24. Frey CU, Röthlisberger C. Social support in healthy adolescents J Youth Adolesc $1996 ; 25: 17-31$.

25. Schreurs KM, de Ridder DT. Integration of coping and social support perspectives: Implications for the study of adaptation to chronic diseases. Clin Psychol Rev 1997;17:89112.

26. Cutrona CE, Russell DW. Type of social support and specific stress: toward a theory of optimal matching. In Sarason BR, Sarason IG, Pierce GE. (Eds), Social support: an interactional view. New York: Wiley c1990. 319 p.

27. Chida Y, Hamer M, Steptoe AA. bidirectional relationship between psychosocial factors and atopic disorders: a systematic review and meta-analysis. Psychosom Med 2008;70:102-116.

28. Bousquet J, Knani J, Dhivert H, Richard A, Chicoye A, Ware JE Jr, Michel FB. Quality of life in asthma. I. Internal consistency and validity of the SF-36 questionnaire. Am J Respir Crit Care Med 1994;149:371-375.

29. Statistics Sweden. [Internet] 2013, Tables of Sweden's population 2009: 131 Population by sex age marital status by county Dec 312009 according to the administrative subdivisions of January 12010 Available from: http://wwwscbse/statistik/_publikationer/BE0101_ 2009A01_BR_05_BE0110TABpdf

30. Palmquist E, Claeson AS, Neely G, Stenberg B, Nordin S. Overlap in prevalence between various types of environmental intolerance. Int J Hyg Envir Heal, 2014;217:427-434.

31. Nordin M, Andersson L, Nordin S. Coping strategies social support and responsibility in chemical intolerance. J Clin Nurs 2010;19:2162-2173. 
32. Taylor SE, Stanton AL. Coping resources coping processes and mental health. Annu Rev Clin Psychol 2007;3:377-401.

33. Austenfeld JL, Stanton AL. Coping through emotional approach: a new look at emotion coping and health-related outcomes. J Pers 2004;72:1335-1364.

34. Yellowlees PM, Ruffin RE. Psychological defenses and coping styles in patients following a life-threatening attack of asthma. CHEST Journal 1989;95:1298-1303.

35. Barton C, Clarke D, Sulaiman N, Abramson M. Coping as a mediator of psychosocial impediments to optimal management and control of asthma. Respir Med 2003;97:747-761.

36. Carver CS, Pozo C, Harris SD, Noriega V, Scheier MF, Robinson DS, Ketcham AS, Moffat FL, Clark KC. How coping mediates the effect of optimism on distress: a study of women with early stage breast cancer. J Pers Soc Psychol 1993;65:375-390.

37. Petsios KT, Priftis KN, Hatziagorou E, Tsanakas JN, Antonogeorgos G, Matziou VN. Determinants of quality of life in children with asthma. Pediatr Pulmonol 2013;48:11711180.

38. Allman E, Berry D, Nasir L. Depression and coping in heart failure patients: a review of the literature. J Cardiovasc Nurs 2009;24:106-117.

39. Sexton DL, Calcasola SL, Bottomley SR, Funk M. Adults' experience with asthma and their reported uncertainty and coping strategies. Clin Nurse Spec 1999;13:8-14.

40. Dakof GA, Taylor SE. Victims' perceptions of social support: What is helpful from whom? J Pers Soc Psychol 1990;58:80-89.

41. Masters KS, Stillman AM, Spielmans GI. Specificity of social support for back pain patients: do patients care who provides what? J Behav Med 2007;30:11-20.

42. Vamos M, Kolbe J. Psychological factors in severe chronic asthma. Aust N Z J Psychiatry 1999;33:538-544. 
43. Clark NM, Nothwehr F. Self-management of asthma by adult patients. Patient Educ Couns 1997;32:5-20.

44. Anastasia A. Psychological Testing. New York: Macmillan. c1988. 
Table 1. Demographics and diagnoses for the participants in Study 1 and 2 with monthly (low) and daily/weekly (high) frequency of asthma/allergy exacerbation and for the entire sample.

\begin{tabular}{|c|c|c|c|c|c|}
\hline & \multicolumn{2}{|c|}{$\begin{array}{c}\text { Study } 1 \\
\text { Coping strategies }\end{array}$} & \multicolumn{2}{|c|}{$\begin{array}{c}\text { Study } 2 \\
\text { Social support }\end{array}$} & \multirow{2}{*}{$\begin{array}{c}\text { Entire } \\
\text { sample } \\
(\mathrm{n}=3406)\end{array}$} \\
\hline & $\begin{array}{c}\text { Low } \\
(\mathrm{n}=124)\end{array}$ & $\begin{array}{l}\text { High } \\
(\mathrm{n}=63)\end{array}$ & $\begin{array}{l}\text { Low } \\
(\mathrm{n}=57)\end{array}$ & $\begin{array}{l}\text { High } \\
(\mathrm{n}=37)\end{array}$ & \\
\hline Women (\%) & 62.9 & 66.7 & 59.6 & 64.9 & 55.7 \\
\hline Age $($ mean $\pm \mathrm{SD})$ & $42.5 \pm 14.8$ & $45.5 \pm 17.4$ & $44.1 \pm 16.0$ & $44.6 \pm 16.7$ & $55.2 \pm 16.8$ \\
\hline Duration of illness (years) & $25.3 \pm 14.1$ & $21.0 \pm 15.3$ & $25.8 \pm 16.3$ & $24.8 \pm 16.4$ & \\
\hline Married/partner (\%) & 76.0 & 69.8 & 69.1 & 70.3 & 73.9 \\
\hline University studies (\%) & 55.7 & 50.0 & 48.2 & 52.8 & 41.8 \\
\hline Smoking regularly (\%) & 8.2 & 11.1 & 10.7 & 16.2 & 8.8 \\
\hline \multicolumn{6}{|l|}{ Physical exercise (\%) } \\
\hline $\begin{array}{l}\text { Once a month or more } \\
\text { seldom }\end{array}$ & 14.0 & 12.7 & 12.5 & 10.8 & 12.9 \\
\hline 2-4 times a month & 27.3 & 23.8 & 26.8 & 32.4 & 20.0 \\
\hline 2-3 times a week & 38.0 & 38.1 & 32.1 & 35.1 & 37.9 \\
\hline More than 3 times/week & 20.7 & 25.4 & 28.6 & 21.6 & 29.2 \\
\hline \multicolumn{6}{|l|}{ Perceived general health (\%) } \\
\hline Excellent & 8.9 & 3.2 & 10.5 & 5.6 & 10.6 \\
\hline Very good & 35.5 & 33.9 & 31.6 & 33.3 & 29.4 \\
\hline Good & 39.5 & 38.7 & 35.1 & 41.7 & 34.2 \\
\hline Fairly good & 14.5 & 19.4 & 19.3 & 16.7 & 22.4 \\
\hline Poor & 1.6 & 4.8 & 3.5 & 2.8 & 3.4 \\
\hline \multicolumn{6}{|l|}{ Physician-based diagnosis (\%) } \\
\hline Allergic asthma & 41.9 & 25.4 & 50.9 & 37.8 & 4.8 \\
\hline Non-allergic asthma & 19.4 & 19.0 & 17.5 & 16.2 & 3.8 \\
\hline Allergic rhinitis & 64.5 & 74.6 & 63.2 & 78.4 & 8.7 \\
\hline Atopic dermatitis & 15.3 & 15.9 & 15.8 & 10.8 & 2.6 \\
\hline One asthma/allergy type & 64.5 & 69.8 & 59.7 & 62.2 & 11.7 \\
\hline Two asthma/allergy types & 29.8 & 25.4 & 33.3 & 32.4 & 3.4 \\
\hline Three asthma/allergy types & 5.6 & 4.8 & 7.0 & 5.4 & 0.5 \\
\hline
\end{tabular}




\begin{tabular}{lccccc} 
Four asthma/allergy types & 0 & 0 & 0 & 0 & 0 \\
MCS* & 3.2 & 12.7 & 5.3 & 16.2 & 3.3 \\
NBRS** & 0.8 & 4.8 & 1.8 & 5.4 & 1.4 \\
\hline
\end{tabular}

*Multiple chemical sensitivity, **Non-specific building-related symptoms 
Table 2. The problem- and emotions-focused statements about coping strategies used for assessment, and analyzed separately.

Problem-focused coping strategies

You ask others to explore the environment before you go to a place you suspect will affect your asthma and/or allergy.

You seek information about asthma and/or allergies.

You seek health care for you asthma and/or allergy.

You avoid environments you know will affect your asthma and/or allergies.

Emotion-focused coping strategies

You try to accept your situation with asthma and/or allergies and make the best of it.

You try to re-prioritize how important different things are to you.

You try not to think about your asthma/allergy.

You make yourself feel better by eating, drinking or smoking. 
Table 3. Results from two-way analyses of variance, separate for problem- and emotion-focused coping, for testing whether type of strategy and frequency of symptom (disease severity) were associated with degree of usage of coping.

\begin{tabular}{lll}
\hline & F-value & p-value \\
\hline Problem-focused & & \\
Type of strategy (TS) & 20.14 & $<0.05$ \\
Frequency of symptom (FS) & 1.30 & 0.309 \\
TS x FS & 1.37 & 0.297 \\
Emotion-focused & & \\
Type of strategy (TS) & 66.27 & $<0.001$ \\
Frequency of symptom (FS) & 0.20 & 0.695 \\
TS x FS & 3.28 & 0.058 \\
\hline
\end{tabular}


Table 4. Results from three-way analyses of variance for testing whether type and source of support and frequency of symptom (disease severity) were associated with degree of social support.

\begin{tabular}{lcc}
\hline & F-value & p-value \\
\hline Type of support (TS) & 60.12 & $<0.001$ \\
Source of support (SS) & 31.75 & $<0.001$ \\
Frequency of symptom (FS) & 7.10 & $<0.05$ \\
TS $\times$ SS & 7.74 & $<0.001$ \\
TS $\times$ FS & 1.13 & 0.323 \\
SS $\times$ FS & 1.12 & 0.346 \\
TS $\times$ SS $\times$ FS & 2.38 & $<0.05$ \\
& & \\
\hline
\end{tabular}

